\title{
$1 \quad$ Inhibition of tRNA Synthetases Induces Persistence in Chlamydia
}

2

3

4

5

6

8

9

10

11

12

13 \#Corresponding Author:

14

15

16

17 leucine
Nathan D. Hatch, Scot P. Ouellette ${ }^{\#}$

${ }^{1}$ Department of Pathology and Microbiology, College of Medicine, University of Nebraska

Medical Center, Omaha, NE

Keywords: Chlamydia, persistence, IFN $\gamma$, amino acid starvation, tRNA synthetases, tryptophan,

Running Title: tRNA synthetase inhibitor effects on Chlamydia

Department of Pathology and Microbiology, College of Medicine, University of Nebraska Medical

Center, 985900 Nebraska Medical Center (DRC2 5022), Omaha, NE

Tel: +1-402-559-0763 Fax: +1-402-559-5900 Email: scot.ouellette@unmc.edu 


\section{Abstract}

Chlamydia trachomatis is the leading cause of bacterial sexually transmitted infections, and $C$. pneumoniae causes community-acquired respiratory infections. In vivo, the host immune system will release interferon-gamma (IFN $\gamma$ ) to combat infection. IFN $\gamma$ activates human cells to produce the tryptophan (trp) catabolizing enzyme, IDO. Consequently, there is a reduction in cytosolic trp in IFN $\gamma$-activated host cells. In evolving to obligate intracellular dependence, Chlamydia has significantly reduced its genome size and content as it relies on the host cell for various nutrients. Importantly, $C$. trachomatis and $C$. pneumoniae are trp auxotrophs and are starved for this essential nutrient when the human host cell is exposed to IFN $\gamma$. To survive this, chlamydiae enter an

27 alternative growth state referred to as persistence. Chlamydial persistence is characterized by a halt in the division cycle, aberrant morphology, and, in the case of IFN $\gamma$-induced persistence, trp codon-dependent changes in transcription. We hypothesize that these changes in transcription are dependent on the particular amino acid starvation state. To investigate the chlamydial response mechanisms acting when other amino acids become limiting, we tested the efficacy of prokaryotic specific tRNA synthetase inhibitors, indolmycin and AN3365, to mimic starvation of trp and leucine, respectively. We show that these drugs block chlamydial growth and induce changes in morphology and transcription consistent with persistence. Importantly, growth inhibition was reversed when the compounds were removed from the medium. With these data, we find that indolmycin and AN3365 are valid tools that can be used to mimic the persistent state independently

37 of IFN $\gamma$. 


\section{Importance}

The obligate intracellular pathogen Chlamydia trachomatis, although treatable, remains a

42 major public health concern due to rising infection rates. The asymptomatic nature of most

43 Chlamydia infections is hypothesized to be a product of its ability to transition into a slow-growing

44 state referred to as persistence. The most physiologically relevant inducer of persistence is the

45 immune cytokine IFN $\gamma$, which in humans activates an enzyme that degrades tryptophan, an

46 essential amino acid that Chlamydia scavenges from the host cell. Unfortunately, the exact timing

47 at which Chlamydia is starved after IFN $\gamma$ treatment is inexact. To mechanistically study

48 persistence using genetic tools, an experimental model where amino acid starvation can be induced

49 at specific times is needed. Here, we demonstrate the capability of tRNA synthetase inhibitors,

50 indolmycin and AN3365, to model persistence independently from the use of IFN $\gamma$. These tools

51 will also allow comparisons between amino acid stress responses in this unique bacterium.

52 Word Count: 149/150 


\section{Introduction}

Chlamydial diseases are significant causes of morbidity in humans. Chlamydia trachomatis is the leading cause of bacterial sexually transmitted infections in the world. In 2017, the U.S. Centers for Disease Control and Prevention received over 1.7 million reports of chlamydial infections (1). This number is likely an underestimate due to most infections being asymptomatic and, therefore, undetected (2). The strains responsible for these infections are primarily confined to the urogenital serovars, D-K, but can also contain those of the invasive serovars, L1-L3. Untreated C. trachomatis urogenital infections can ascend the genital tract, potentially leading to pelvic inflammatory disease and tubal factor infertility (3). Chlamydia pneumoniae is a respiratory pathogen responsible for approximately $10 \%$ of community acquired cases of pneumonia. The presence of antibodies in over $50 \%$ of adults in the United States, as well as several other countries, suggests infection with C. pneumoniae is relatively common (see (4) for extended review). Additionally, long term sequelae such as atherosclerosis and adult-onset asthma have been associated with C. pneumoniae infection $(5,6)$.

Chlamydiae are obligate intracellular bacteria that require a host cell to complete their developmental cycle. Chlamydial development involves interconversion between two distinct developmental forms: the elementary body (EB) and the reticulate body (RB). EBs are infectious, metabolically quiescent, environmentally stable, and compact in size $(0.3 \mu \mathrm{m})$. RBs are the noninfectious, metabolically active, replicative form that measure approximately $0.8 \mu \mathrm{m}$ in diameter (as reviewed in (7)). After initial attachment, EBs are internalized into an endocytic vesicle of the host cell and begin primary differentiation into RBs. Soon thereafter, chlamydial proteins are secreted into the vesicle membrane and host cell cytosol to prevent targeting of the chlamydialcontaining vacuole to the lysosome. This modified endosome is known as the chlamydial inclusion 
and is a protective vacuole that masks the invading organisms from host cell defenses for the entirety of their development (8). Following the establishment of the inclusion and primary differentiation into an $\mathrm{RB}$, the organism rapidly multiplies by a polarized budding mechanism (9). Chlamydia asynchronously undergo secondary differentiation into EBs until the organisms are released from the cell through lysis or extrusion. The duration of this developmental process is approximately 48 hours for C. trachomatis or 72 hours for the slower growing C. pneumoniae.

During infection, host immune cells respond to Chlamydia by releasing the cytokine interferon-gamma (IFN $\gamma$ ) (10). IFN $\gamma$ will bind its receptor and activate multiple signaling pathways. The major IFN $\gamma$-induced antichlamydial effector in human cells is indoleamine 2,3dioxygenase (IDO) (11). IDO will catabolize cytosolic tryptophan (trp) into N'-formylkynurenine, a metabolite that cannot be used by $C$. trachomatis or $C$. pneumoniae (11-14). Although IFN $\gamma$ regulates over 200 human genes (15), IDO expression, with the resulting depletion of available trp $(16,17)$ and decrease in translation $(18)$, is the driving factor for inhibiting chlamydial growth (Figure 1). This is supported by the ability to restore growth in cell culture by adding additional mutant cells (19-21). grow, they must respond to this starvation condition to maintain viability (22). Interestingly, Chlamydia has eliminated the stringent response ( $\mathrm{relA} / \mathrm{spoT}$ ), which is used by most eubacteria to respond to amino acid starvation $(22,23)$. This raises the intriguing question of how they respond to amino acid limitation. Phenotypically, chlamydial RBs transition into an alternative developmental state termed persistence to cope with this stress (16). Persistent chlamydiae are thought to be associated with the chronic sequelae linked to chlamydial diseases. Importantly, 
99

100

101

102

103

104

105

106

107

108

109

110

111

112

113

114

various stressors can trigger persistence and not all persistent transcriptomic and proteomic responses are the same (as reviewed in (24)). Nevertheless, persistence models are characterized by bacteria (i) remaining viable yet non-infectious, (ii) being non-replicative, (iii) exhibiting an aberrant morphology, (iv) and reactivating to resume the development cycle after the stress is removed $(18,25)$. Importantly, and as it relates to IFN $\gamma$-induced persistence, transcriptomic and proteomic changes also occur, and these changes are predictable based on the trp content of the transcript or protein (26).

The mechanisms for entry into, maintenance of, and exit from persistence are not known, and investigation of these mechanisms is made difficult by the nature of inducing persistence through IFN $\gamma$ exposure. Therefore, it is important to be able to study Chlamydia's transition into persistence while simultaneously controlling for as many variables as possible, demonstrating a need for an amino acid starvation model without the confounding variables that come with using IFN $\gamma$. In an effort to reproduce and model IFN $\gamma$-induced persistence in the absence of IFN $\gamma$, the most straightforward approach is to remove trp from the culture medium. However, this will induce host cell autophagy and lysosomal degradation of proteins, which can regenerate amino acid pools that Chlamydia can scavenge (27).

We hypothesized that bacterial tRNA synthetase inhibitors would offer an alternative pathway to decrease translation in Chlamydia in an amino acid-dependent manner (Figure 1). These inhibitors would, therefore, afford an opportunity to specifically mimic starvation for different amino acids to compare and contrast amino acid starvation responses in Chlamydia. We show that combining trp depleted media with the trp analog, indolmycin, is sufficient to induce persistence in Chlamydia in cell culture. Indolmycin is a tryptophanyl-tRNA synthetase inhibitor that acts through competitive inhibition as a trp analog (28). Additionally, AN3365, a leucyl-tRNA 
122 synthetase inhibitor, was used in this study to investigate the possibility of inducing persistence

123 through the starvation of an amino acid other than trp. AN3365 is an antibiotic in the aminomethyl

124 benzoxaborole class shown to be active against Gram-negative bacteria (29). Unlike indolmycin,

125 AN3365 is a non-competitive inhibitor of bacterial leucyl-tRNA synthetases that locks the protein

126 in its editing conformation, preventing release of charged leucyl-tRNAs (29). These tools will

127 facilitate the modeling of specific amino acid starvation responses in Chlamydia without affecting

128 the host cells. Here, we validate the use of these compounds, indolmycin and AN3365, as tools

129 that can be used within the chlamydial field to investigate mechanisms engaged by Chlamydia to

130 enter, maintain, and exit persistence in response to amino acid starvation. 


\section{Results}

\section{The bacterial tRNA synthetase inhibitors indolmycin and AN3365 block chlamydial growth.}

To determine whether the bacterial tRNA synthetase inhibitors indolmycin and AN3365 were effective against Chlamydia, we measured inclusion forming units (IFU) as a metric for chlamydial growth in the presence and absence of the inhibitors. Initial empirical experiments with indolmycin, a competitive inhibitor for tryptophanyl-tRNA charging, revealed that it had an impact on growth at $120 \mu \mathrm{M}$ or higher and in the presence of $1 \mathrm{mg} / \mathrm{L}$ trp or lower (data not shown). We chose to perform this and all subsequent experiments with indolmycin by adding it at $120 \mu \mathrm{M}$ concentration in the absence of trp at $10 \mathrm{hpi}$. Under these conditions, indolmycin treatment reduced the generation of IFUs to the limit of detection of the assay (Figure 2A). To determine the effective concentration for AN3365, we performed a dose response assay and observed that concentrations in excess of $250 \mathrm{ng} / \mathrm{mL}$ (added at $10 \mathrm{hpi}$ ) were sufficient to reduce chlamydial growth to basal levels (i.e. near limit of detection, Fig. 2B). Importantly, as a non-competitive inhibitor of leucyltRNA charging, AN3365 was effective in the presence of normal media levels of leucine (105 mg/L). AN3365 was also effective at blocking chlamydial growth when added at various time points up to 12 hpi during the developmental cycle (Fig. 2C). From these data, we conclude that indolmycin and AN3365 effectively blocked chlamydial growth. Nevertheless, a lack of recoverable IFUs suggests one of three outcomes: i) complete loss of viability, ii) decrease in the rate of development (i.e. prolonged RB-only phase), or iii) entry into persistence.

\section{Indolmycin and AN3365 induce morphological aberrance in $C$. trachomatis.}


To help distinguish between the possible reasons for a loss in recoverable IFUs, immunofluorescence microscopy was used to analyze chlamydial morphology (Fig. 3). HEp-2 cells were infected with $C$. trachomatis serovar L2, treated or not with the indicated compounds at 10 hpi or pre-treated with IFN $\gamma$ as described in Materials and Methods, and fixed and processed individual organisms, similar to that observed during IFN $\gamma$ treatment (16). Electron microscopic analysis of organisms treated with inhibitors also revealed aberrant morphology (Suppl. Fig. 1). Interestingly, the labeling of MOMP was not uniform around the membrane of the organisms in of L or W may therefore negatively impact translation of MOMP that in turn may lead to nonuniform localization along the organism's membrane (see also (16)). Conversely, Hsp60_1, which contains $0 \mathrm{~W}$ codons, appeared abundant in both indolmycin and IFN $\gamma$-treated samples.

164 Interestingly, Hsp60_1 is also abundant in the AN3365 treated sample despite the presence of 45 induced persistence (12). Taken together, these morphological data in conjunction with the IFU data presented above support the conclusion that the organisms are non-replicative, display an aberrant morphology, and are not proceeding through the normal developmental cycle.

\section{Removal of indolmycin and AN3365 rescues C. trachomatis growth and morphology.}

A key characteristic of persistence is its reversibility such that the organism can revert back

172 to a developmentally competent RB. To determine whether or not C. trachomatis remains viable

173 under indolmycin or AN3365 treatment, we attempted to rescue the organisms by removing each

174 treatment (Fig. 4). HEp-2 cells were infected with C. trachomatis serovar L2 and treated or not 
175 with the designated compounds at $10 \mathrm{hpi}$. Treatment media was aspirated at $24 \mathrm{hpi}$, and samples

176

177

178

179

180

181

182

183

184

185

186

187

188

189

190

191

192

193

194

195

196

197

were washed 3x with DPBS before replenishing with DMEM. After 24 and 48 hour recovery

periods following drug removal, IFUs were quantified and organism morphology was assessed. In

the presence of indolmycin and AN3365, chlamydial growth was inhibited up to 72 hpi (Figure

4A). After removal of these compounds from the medium, chlamydial growth was restored as represented by a logarithmic increase in IFUs at 48 (24h post recovery) and 72 (48h post recovery) hpi. These IFU data were corroborated by the detection of normal morphological forms at these time points that were indistinguishable from 24 and 48 hpi untreated organisms (Figs. 4B-D). Moreover, recoverable IFUs were intermediate between that observed at the 24 and 48 hpi untreated groups. This is expected when considering treatment time at 10 hpi essentially pauses the development cycle. After 24 hours of recovery, the organisms have undergone approximately 34 hours of development. We conclude that the effects of indolmycin and AN3365 are reversible, consistent with what is observed during the removal of IFN $\gamma$ from persistent cultures $(18,25,30)$. Collectively, the data presented in Figures 2-4 indicate that the tRNA synthetase inhibitors induce a persistent growth state that is reversible upon removal of the compounds.

\section{Indolmycin and AN3365 induce morphological aberrance in $C$. pneumoniae.}

Although the underlying mechanisms of persistence are unknown, we hypothesize that they are conserved between $C$. trachomatis and C. pneumoniae. C. pneumoniae is a slower growing species compared to C. trachomatis, particularly the L2 serovar, suggesting it would be equally, if not more, sensitive to tRNA synthetase inhibitors. Therefore, we suspected the use of indolmycin and AN3365 on C. pneumoniae would produce a phenotype similar to that observed during IFN $\gamma$ exposure. To test this, we infected HEp-2 cells with C. pneumoniae AR39. Samples were treated 
or not with the designated compound at 24 hpi or with IFN $\gamma$ at time of infection. As seen in Figure 5, the morphologies of organisms treated with indolmycin or AN3365 closely resemble those treated with IFN $\gamma$. We conclude from these data that tRNA synthetase inhibitors are broadly applicable to study persistence in Chlamydia species.

\section{The bacterial tRNA synthetase inhibitors induce transcriptional changes consistent with}

IFN $\gamma$-mediated persistence.

To determine whether the tRNA synthetase inhibitors induce transcriptional changes consistent with persistence, nucleic acids were isolated from infected cultures, and the abundance of selected transcripts was measured and normalized to genomic DNA content. Increased transcription of euo has been previously associated with $\operatorname{IFN} \gamma$-mediated persistence $(18,30)$. This elevated transcriptional response was observed in both $C$. trachomatis (beginning at 4 h post treatment) and C. pneumoniae when exposed to either indolmycin or AN3365 treatments and resembled IFN $\gamma$-induced persistence (Fig. 6A). In addition to euo, groEL_l has also been implicated in persistence and general stress response (30). We analyzed the abundance of groEL_l transcripts in both $C$. trachomatis and $C$. pneumoniae under each treatment (Fig. 6B). In agreement with previous findings, groEL_l transcripts remained unchanged $(<1.5 \mathrm{x}$ difference $)$ in $C$. trachomatis between 10 and $24 \mathrm{hpi}$ in IFN $\gamma$-treated samples, whereas groEL_l transcripts decreased in abundance during the same timeframe in the untreated samples (18). Interestingly, indolmycin-treated samples closely mirrored the effects of IFN $\gamma$ while AN3365 treatment resulted in a 4-5 fold increase of groEL_l transcripts at the 24 hour time point. Conversely, for $C$. pneumoniae, all treatment conditions followed a similar transcript pattern as in untreated samples for groEL_1. This is also consistent with previous observations for IFN $\gamma$-induced persistence in 
221 this organism (18). Additionally, indolmycin treatment resulted in a rapid (4h) and large increase

222

223

224

225

226

227

228

229

230

231

232

233

234

235

236

237

238

239

240

241

242

243 in $\operatorname{trp} B$ transcripts ( $C$. pneumoniae does not encode $\operatorname{trp} B$ ), a gene that is repressed under trp-replete conditions (Fig. 6C and (31)). This suggests C. trachomatis has detected and is quickly responding to a lack of trp. Moreover, there is a noticeable increase in $\operatorname{trp} B$ transcripts at 24 hpi following AN3365 treatment (3-4 fold increase). Considering the lack of change observed at 14 hpi, the increase of $\operatorname{trp} B$ transcripts at 24 hpi may be an indirect effect caused by a cascade of responses rather than an immediate reaction to leu limitation. It is important to note that while C. trachomatis detects trp limitations when cultured in trp-deplete media (no indolmycin), the abundance of euo transcripts does not change (Suppl. Fig. 2). Therefore, removing trp from the medium cannot be used as a reliable IFN $\gamma$-free model for persistence, particularly for faster growing species and strains of Chlamydia.

\section{Transcript levels of the 3 ' end of the ytg operon are reduced in Chlamydia during indolmycin}

\section{or AN3365 treatment.}

To determine whether indolmycin and AN3365 could mimic a more nuanced characteristic of IFN $\gamma$-induced persistence, we looked to the $y \operatorname{tg} A B C D$ operon (26). As previously described by Ouellette et al. (32), IFN $\gamma$ treatment results in Rho-dependent polarization of the $y t g$ operon. This results in a skewed ratio of $y \operatorname{tg} A: y \operatorname{tg} D$ transcripts. During the normal developmental cycle, this ratio is approximately 5-10 but increases to over 30 -fold or higher during IFN $\gamma$-mediated trp starvation. We hypothesized that this skew was caused by ribosome stalling along the transcript due to the lack of charged tRNAs, which allows Rho to bind internal rut sites to terminate transcription prematurely (32). Of note, within the $y \operatorname{tg} C$ gene is the presence of three tandem $\mathrm{W}$ codons, and the gene encodes additional W residues. L residues are highly abundant in the operon 
244 with 98 total residues in $y \operatorname{tg} B$ and $y \operatorname{tg} C$ and a total of 11 LL motifs in C. trachomatis. We reasoned 245 that both indolmycin and AN3365 should produce the same phenotype as a result of the stalling 246 of ribosomes on trp codons, in the case of indolmycin treatment, or leu codons, in the case of 247 AN3365 treatment, respectively. We quantified $y \operatorname{tg} A$ and $y \operatorname{tg} D$ transcripts at different times after 248 addition of the tRNA synthetase inhibitors (at 10hpi for Ctr, 24hpi for Cpn) and compared the 249 ratios to those from IFN $\gamma$-treated cultures. As anticipated, both indolmycin and AN3365 treated 250 samples resembled the IFN $\gamma$-induced persistent state with regards to the polarity of the $y \operatorname{tg}$ operon, 251 shown in Figure 7 as a disproportionate level of $y \operatorname{tg} A$ to $y \operatorname{tg} D$ transcripts. Interestingly, differences 252 in the $\operatorname{Ctr} y \operatorname{tg} A: y \operatorname{tg} D$ ratio were observed within four hours of treatment (14hpi) and were more 253 pronounced for L limitation (AN3365) than for W limitation (indolmycin or IFN $\gamma$ ) (Fig. 6A). This 254 is consistent with the larger number of L versus W residues in the operon. However, by 24hpi, the $255 y \operatorname{tg} A: y \operatorname{tg} D$ ratio for all treatments was similar, possibly reflecting a recovery in read-through 256 potential in AN3365-treated cultures. For Cpn, all treatments resulted in the expected increase in $257 y \operatorname{tg} A$ transcripts in proportion to $y \operatorname{tg} D$ transcripts when measured at 48hpi (after treatment at 258 24hpi). Overall, these data demonstrate that the tRNA synthetase inhibitors recapitulate key 259 characteristics of amino acid starvation in Chlamydia. 


\section{Discussion} immunological basis for inducing persistence in cell culture was first described by Beatty et al. in 1993, who described the effects of IFN $\gamma$, and its reversibility, on chlamydial growth and morphology in human cell lines $(12,16,25)$. These effects were connected with the ability of human IFN $\gamma$ to induce a tryptophan-limiting environment in the cell by activating IDO expression

267 (12). Broadly speaking, these effects are likely mediated by the inability to efficiently translate

268 key proteins enriched in trp residues (see Fig.1 and (18, 33, 34)). More recent studies have 269 characterized transcriptional and translational changes associated with IFN $\gamma$-mediated persistence $270(18,30)$. More importantly, these "persistence" characteristics as defined in cell culture models 271 have recently been observed in patient samples (13). This underscores the need to have a better 272 mechanistic understanding of how amino acid limitation results in a persistent phenotype. Chlamydia trachomatis serovar L2 (35). This advance, common for decades in other bacterial systems, has allowed fluorescent tagging of target proteins and reverse genetic tools to be applied to Chlamydia (36-40). However, serovar L2 is among the fastest growing strains of C. trachomatis

277 (41), and slower growing strains and species of Chlamydia have proven more difficult to 278 transform. As it relates to genetic studies of IFN $\gamma$-induced persistence, this creates a hurdle. When

279 IFN $\gamma$ is added to cell cultures, removal of trp from the cytosol by IDO is gradual and takes approximately $24 \mathrm{~h}$. This is a time during the L2 developmental cycle when RBs are differentiating

281 to EBs and EBs are rapidly accumulating (e.g. Fig. 2A). For IFN $\gamma$ to be effective, pretreatment of 282 host cells with IFN $\gamma$ prior to infection is required, yet this strategy is inconsistent. To induce a persistent state in serovar L2, we recently published a protocol that described the pretreatment of 
284 cells with IFN $\gamma$ prior to infection followed by the addition of IFN $\gamma$-conditioned medium at 10 hpi

285 (32). This allows IDO to be sufficiently expressed and trp to be catabolized, resulting in small

286 inclusions that contain relatively few aberrant organisms approximately 24 hours post infection

287 (hpi). While this protocol elicited reproducibly persistent forms for us, differences between labs,

288 the cell types used, and batches of IFN $\gamma$ (which require careful titration for effective dose) may

289 not make it easily transferable to other systems. This can lead to discrepancies in findings since

290 too much IFN $\gamma$ exposure prevents primary differentiation of chlamydial EBs to RBs, while too

291 little results in mixed populations of persistent and normal organisms within a culture (20). In sum,

292 the field would benefit greatly from a tool that allows reproducible induction of persistence and

293 that minimizes confounding variables while maximizing control and flexibility of experimental

294 design parameters.

Here, we sought to evaluate the effects of characterized bacterial tRNA synthetase inhibitors $(28,29,42)$ for their ability to induce persistence in Chlamydia as a first step in

297 developing systems that would allow us to mechanistically address this alternative growth state.

298 Such an approach would offer immediate advantages over IFN $\gamma$-mediated tryptophan limitation in 299 that a translation block (i.e. starvation mimicking condition) could be induced immediately upon 300 addition of the inhibitors. By using E. coli tRNA turnover rates as a guide, we hypothesize that the 301 pool of charged trp-tRNA or leu-tRNA would be depleted within seconds after treatment (43).

302 This would allow more direct comparisons between research groups with less variability in 303 experimental systems. In particular, the use of inhibitors circumvents the host cell's ability to 304 regenerate amino acid pools through autophagy, which would occur in conditions where an amino 305 acid is omitted from culture medium. Indeed, we observed that, under such conditions, although 306 the absence of trp was sensed, as demonstrated by increased $\operatorname{trp} B$ transcripts, euo transcripts, a 
marker of persistence, did not increase (Suppl. Fig. 2). This suggests that, for serovar L2, simply omitting amino acids from the culture medium is not sufficient to induce a bona fide persistence response.

These data indicate the ability of indolmycin and AN3365 to induce persistence by limiting Chlamydia's use of a single specific amino acid by blocking the charging of its cognate tRNA. Considering the parallels in morphology, transcriptional response, and mode of stress caused by these compounds in comparison to IFN $\gamma$, we conclude that the use of indolmycin and AN3365 in place of IFN $\gamma$ is a viable method to study amino acid starvation stress responses. Interestingly, indolmycin treatment replicates the key transcriptional and morphological phenotypes associated with IFN $\gamma$-induced persistence, further supporting that tryptophan limitation is the main antichlamydial inhibitory mechanism of IFN $\gamma$ in human cells $(11,19)$. The transcriptional changes of $C$. pneumoniae in response to the inhibitors more closely mirrored IFN $\gamma$-mediated persistence than $C$. trachomatis did. Given the slower growth rate of $C$. pneumoniae, this is not surprising. The greater heterogeneity in transcription responses between indolmycin and IFN $\gamma$ in $C$. trachomatis may be due to the organism's quicker developmental cycle and asynchronous nature. That being said, the difference between the tryptophan starvation condition in C. pneumoniae versus $C$. trachomatis was not more than four-fold and showed the same trends overall.

AN3365-induced leu starvation displayed noteworthy differences from the trp starvation conditions. Firstly, groEL_l transcripts generally increased during the analysis in C. trachomatis. This is consistent with what we previously characterized as codon-dependent transcriptional changes during amino acid starvation as Hsp60_1 contains 45 L residues (26). Secondly, $\operatorname{trp} B$ transcripts were not increased $4 \mathrm{~h}$ after treatment, as expected since leu starvation should not activate expression of the $\operatorname{trp} R B A$ operon. However, 14h post treatment, there was an 
approximately 3 -fold increase in $\operatorname{trp} B$ levels, suggesting some de-repression of the operon. $\operatorname{TrpR}$ contains 11 leu residues including one LL motif. Therefore, the inability to efficiently translate the repressor over time may allow for gradual transcriptional activation of the operon. Alternatively, the recently described role for the iron-sensitive repressor, YtgR, in blocking transcription of $\operatorname{trp} B A$, may also be important (44). The YtgCR protein contains approximately 60 leu residues with multiple LL motifs that likely prevent efficient translation of this sequence. This is under investigation, but we also observed transcriptional changes in the ytg operon (see below).

We recently demonstrated differences in transcript levels between the 5' and 3' ends of large monocistronic and polycistronic transcripts (26). We further connected this to Rhodependent polarity prematurely terminating transcription in trp-codon rich transcripts during IFN $\gamma$ mediated trp starvation (32). To determine whether the tRNA synthetase inhibitors could replicate the destabilization of the 3 ' end of a large transcript, we analyzed the abundance of the $y \operatorname{tg} A$ and $y \operatorname{tg} D$ transcripts. Consistent with what was previously observed for IFN $\gamma$-mediated trp starvation, both indolmycin and AN3365 caused a disparity in transcript abundance between the 5' and 3' ends of the $y \operatorname{tg}$ operon. Interestingly, AN3365 caused a quick destabilization of $y \operatorname{tg} D$ transcripts in C. trachomatis before recovering to levels observed in trp starvation conditions. The reasons for this are not clear but are under investigation.

The tools described here to mimic specific amino acid starvation states, by blocking tRNA charging, in the absence of chemokines or other significant alterations to culture conditions will facilitate broad comparisons of chlamydial persistence between species. For example, C. caviae resists IFN $\gamma$-mediated persistence by recycling the product of trp degradation, Nformylkynurenine, through a trp scavenging pathway (45). Indolmycin treatment will facilitate studies of trp starvation responses in this species. Likewise, these treatments can be used in mouse 
353 cells, where IDO is not the primary antichlamydial effector $(10,46)$. Also of interest are other 354 intracellular pathogens such as Coxiella or Rickettsia, as studying their response mechanisms to 355 amino acid starvation could lead to a greater understanding of evolutionary strategies employed 356 by obligate intracellular pathogens, which typically lack functional stringent responses, to adapt 357 to this stress.

Following the validation of these compounds as tools to study persistence, we aim to 359 further investigate the role of amino acid limitation in regulating the persistent state. With the 360 ability to limit an amino acid other than trp, we can more rigorously test the hypothesis that trp 361 limitation increases transcription of trp codon containing genes to determine if this is a broad 362 response to amino acid limitation or perhaps something specific to trp (26). We can now also apply 363 genetic tools to study amino acid starvation responses in C. trachomatis L2. 


\section{Materials and Methods}

366

367

368

369

370

371

372

373

374

375

376

377

378

379

380

381

382

383

384

385

386

Organisms and cell culture. The human epithelial cell line HEp-2 was routinely cultivated at $37^{\circ} \mathrm{C}$ with $5 \% \mathrm{CO}_{2}$ in Dulbecco's modified Eagle medium (DMEM; Gibco, Dun Laoghaire, Ireland) supplemented with 10\% FBS. The HEp-2 cells were a kind gift of $\mathrm{H}$. Caldwell (NIH/NIAID). C. trachomatis serovar L2 and C. pneumoniae AR39 EBs were harvested from infected HEp-2 cell cultures at $37^{\circ} \mathrm{C}$ and $35^{\circ} \mathrm{C}$, respectively, with $5 \% \mathrm{CO}_{2}$ and density gradient purified. Purified EBs were titered for infectivity by determining inclusion-forming units (IFU) on fresh cell monolayers. All bacterial and eukaryotic cell stocks were confirmed to be Mycoplasma negative using the LookOut Mycoplasma PCR Detection Kit (Sigma, St. Louis, MO).

Indolmycin was purchased from Cayman Chemical (Ann Arbor, MI) and resuspended to $120 \mathrm{mM}$ in dimethyl sulfoxide (DMSO; Sigma). Aliquots were kept at $-80^{\circ} \mathrm{C}$ and used only once to avoid freeze-thawing. Indolmycin was used at $120 \mu \mathrm{M}$ and added at $10 \mathrm{hpi}$ (C. trachomatis) or 24 hpi (C. pneumoniae) in all experiments. Immediately prior to treatment, cell medium was replaced with DMEM lacking trp (made in-house) to enhance the inhibitory effects of indolmycin. DMEM lacking trp was made using $10 \%$ fetal bovine serum that had been dialyzed to remove any additional amino acids. All custom medium components were purchased from Sigma.

AN3365 was purchased from Cayman Chemical and resuspended to $5 \mathrm{mg} \mathrm{mL}^{-1}$ in DMSO. Aliquots were kept at $-20^{\circ} \mathrm{C}$ and allowed one additional freeze-thaw. AN3365 concentration was titrated to induce persistence without completely stalling development and was used at $1 \mu \mathrm{g} \mathrm{mL}-1$ with treatment at 10 hpi (C. trachomatis) or 24 hpi (C. pneumoniae). No modifications to DMEM 
387

388

389

390

391

392

393

394

395

396

397

398

399

400

401

402

403

404

405

406

407

408

were necessary. In some experiments with $C$. trachomatis, AN3365 was added at different concentrations or at different times post-infection as indicated, with IFU samples collected at 24hpi.

Recombinant human interferon gamma (IFN $\gamma$ ) was purchased from Cell Sciences (Canton, MA) and resuspended to $100 \mu \mathrm{g} \mathrm{ml}^{-1}$ in $0.1 \%$ bovine serum albumin (BSA; Sigma) diluted in water. Aliquots were frozen at $-80^{\circ} \mathrm{C}$ and used only once to avoid freeze-thawing. IFN $\gamma$ was titrated for its effect to induce persistence without killing the bacteria and, in our experiments, $0.5 \mathrm{ng} \mathrm{ml}^{-1}$ was added to cells approximately $11 \mathrm{~h}$ prior to infection. Medium was replaced at $10 \mathrm{hpi}$ with IFN $\gamma$ conditioned medium (ICM) to induce persistence in C. trachomatis as described (32). ICM was prepared by adding $2 \mathrm{ng} \mathrm{ml}^{-1} \mathrm{IFN} \gamma$ to uninfected HEp-2 cells for approximately $54 \mathrm{~h}$ prior to collection and filtration of the medium. C. pneumoniae experiments were treated with $2 \mathrm{ng} \mathrm{ml^{-1 }}$ at the time of infection.

Inclusion Forming Unit (IFU) assays. Infectious progeny were determined based on inclusions formed from a secondary infection. Primary infection samples were harvested by scraping cells in 2 sucrose-phosphate (2SP) solution. Samples were lysed via a single freeze-thaw cycle and allowed to infect a fresh cell monolayer. Titers were enumerated by immunofluorescence.

Immunofluorescent microscopy. Cells were cultured on glass coverslips in 24-well tissue cultures plates and infected with C. trachomatis at an MOI of 1 or C. pneumoniae at an MOI of 2. All cells were fixed in $100 \%$ methanol. Organisms were stained using a primary goat or mouse 
antibody specific to either $C$. trachomatis or $C$. pneumoniae major outer membrane protein (MOMP), respectively, and a donkey anti-goat or anti-mouse secondary antibody conjugated to Alexa Fluor 488 (Jackson Labs, Bar Harbor, Maine). Where applicable, a primary mouse (Ctr) or rabbit (Cpn) antibody specific to chlamydial Hsp60 was also used in conjunction with a secondary donkey anti-mouse or anti-rabbit antibody conjugated to Alexa Fluor 594 (Jackson Labs).

Nucleic acid extraction and RT-qPCR. RNA extraction was performed on infected cell monolayers using TRIzol (Invitrogen/ThermoFisher). Samples were treated with Turbo DNAfree (Ambion/Thermofisher) according to the manufacturer's instructions to remove DNA contamination. cDNA was synthesized from DNA-free RNA using random nonamers (New England BioLabs, Ipswich, MA) and SuperScript III RT (Invitrogen/ThermoFisher) per manufacturer's instructions. Reaction end products were diluted 10 fold with molecular biologygrade water, aliquoted for later use, and stored at $-80^{\circ} \mathrm{C}$. Equal volumes of each reaction mixture were used in $25 \mu \mathrm{L}$ qPCR mixtures with SYBR green master mix (Applied Biosystems) and quantified on a Quant Studio 3 (Applied Biosystems/ThermoFisher) using the standard amplification cycle with a melting curve analysis. Results were compared to a standard curve generated against purified C. trachomatis L2 or C. pneumoniae genomic DNA as appropriate. DNA samples were collected from replicate wells during the same experiments using the DNeasy Blood and Tissue kit (Qiagen, Hilden, Germany). Equal total DNA quantities were used in qPCR with a groEL1 primer set to quantify chlamydial genomes. Genome values were used to normalize respective transcript data. RT-qPCR results were normalized for efficiency with typical results demonstrating $\mathrm{r}^{2}>0.995$ and efficiencies greater than $90 \%$. 
432 Reactivation. To determine the possibility of recovery from persistence, samples were treated or not with AN3365 or indolmycin as described above. After 24 hours post infection, all samples were washed three times with DPBS and given fresh medium. Samples were allowed to recover

435 for an additional 24 or 48 hours before collection for IFU assay or fixation for immunofluorescent microscopy.

Electron Microscopy. HEp-2 cells were cultured in a 6-well plate and infected with $C$. at $10 \mathrm{hpi}$. Cells were trypsinized at $24 \mathrm{hpi}$ and pelleted at $500 \mathrm{xg}$ for 5 minutes. Pellets were washed

$4412 \%$ glutaraldehyde, 2\% paraformaldehyde, and 0.1M Sorenson's phosphate buffer, $\mathrm{pH}$ 7.2. Post

442 fixation was carried out using 1\% Osmium Tetroxide followed by a dehydration series in 443 increasing EtOH concentrations. $90 \mathrm{~nm}$ sections were cut using a Leica UC6 Ultramicrotome with 444 a Diatome diamond knife. Sections were stained in 2\% Uranyl Acetate and Reynold's Lead Citrate. 445 Images were collected on an FEI Tecnai G2 TEM operated at $80 \mathrm{Kv}$.

\section{Acknowledgements}

448 This work was supported by start-up funds from the University of Nebraska Medical Center as 449 well as a CAREER award (1810599) from the National Science Foundation to SPO. We thank Dr.

450 H. Caldwell (NIAID/NIH) for eukaryotic cell stocks and the antibody to C. pneumoniae MOMP,

451 Dr. R. Morrison (UAMS) for the antibody to chlamydial Hsp60_1, Dr. E. Rucks (UNMC) for the 452 antibody against Chlamydia and for critical review of the manuscript, and Dr. R. Carabeo (UNMC) 453 for critical review of the manuscript. We would also like to thank Tom Bargar and Nicholas 
454 Conoan of the Electron Microscopy Core Facility (EMCF) at the University of Nebraska Medical

455 Center for technical assistance. The EMCF is supported by state funds from the Nebraska Research

456 Initiative (NRI) and the University of Nebraska Foundation, and institutionally by the Office of

457 the Vice Chancellor for Research.

458 This publication's contents and interpretations are the sole responsibility of the authors.

459 We declare that we have no conflict of interest. 


\section{Literature Cited}

462 1. CDC. 2018. Sexually Transmitted Disease Surveillance 2017. Services AUSDoHaH, $463 \quad$ Atlanta: U.S. Department of Health and Human Services.

464 2. Satterwhite CL, Torrone E, Meites E, Dunne EF, Mahajan R, Ocfemia MC, Su J, Xu F, Weinstock H. 2013. Sexually transmitted infections among US women and men:

466 prevalence and incidence estimates, 2008. Sex Transm Dis 40:187-93.

467 3. Brunham RC, Maclean IW, Binns B, Peeling RW. 1985. Chlamydia trachomatis: Its Role in Tubal Infertility. The Journal of Infectious Diseases 152:1275-1282.

469 4. Kuo CC, Jackson LA, Campbell LA, Grayston JT. 1995. Chlamydia pneumoniae (TWAR). Clinical microbiology reviews 8:451-461.

471 5. Saikku P, Leinonen M, Mattila K, Ekman MR, Nieminen MS, Makela PH, Huttunen JK, Valtonen V. 1988. Serological evidence of an association of a novel Chlamydia, TWAR, with chronic coronary heart disease and acute myocardial infarction. Lancet 2:983-6.

474 6. Hahn DL. 1995. Treatment of Chlamydia pneumoniae infection in adult asthma: a before475 after trial. J Fam Pract 41:345-51.

476 7. AbdelRahman YM, Belland RJ. 2005. The chlamydial developmental cycle. FEMS

477 Microbiology Reviews 29:949-959. 
478 8. Moore ER, Ouellette SP. 2014. Reconceptualizing the chlamydial inclusion as a

479

480

481

482

483

484

485

486

487

488

489

490

491

492

493

494

495

496 pathogen-specified parasitic organelle: an expanded role for Inc proteins. Frontiers in Cellular and Infection Microbiology 4.

9. Abdelrahman Y, Ouellette SP, Belland RJ, Cox JV. 2016. Polarized Cell Division of Chlamydia trachomatis. PLOS Pathogens 12:e1005822.

10. Perry LL, Feilzer K, Caldwell HD. 1997. Immunity to Chlamydia trachomatis is mediated by T helper 1 cells through IFN-gamma-dependent and -independent pathways. The Journal of Immunology 158:3344.

11. Byrne GI, Lehmann LK, Landry GJ. 1986. Induction of tryptophan catabolism is the mechanism for gamma-interferon-mediated inhibition of intracellular Chlamydia psittaci replication in T24 cells. Infect Immun 53:347-51.

12. Beatty WL, Morrison RP, Byrne GI. 1994. Immunoelectron-microscopic quantitation of differential levels of chlamydial proteins in a cell culture model of persistent Chlamydia trachomatis infection. Infection and immunity 62:4059-4062.

13. Lewis ME, Belland RJ, AbdelRahman YM, Beatty WL, Aiyar AA, Zea AH, Greene SJ, Marrero L, Buckner LR, Tate DJ, McGowin CL, Kozlowski PA, O'Brien M, Lillis RA, Martin DH, Quayle AJ. 2014. Morphologic and molecular evaluation of Chlamydia trachomatis growth in human endocervix reveals distinct growth patterns. Frontiers in Cellular and Infection Microbiology 4. 
497 14. Pfefferkorn ER. 1984. Interferon gamma blocks the growth of Toxoplasma gondii in human fibroblasts by inducing the host cells to degrade tryptophan. Proceedings of the National Academy of Sciences of the United States of America 81:908-912.

500

501

502

503

504

505

506

507

508

509

510

511

512

19. Ibana JA, Belland RJ, Zea AH, Schust DJ, Nagamatsu T, AbdelRahman YM, Tate DJ,

15. Boehm U, Klamp T, Groot M, Howard JC. 1997. Cellular responses to interferongamma. Annu Rev Immunol 15:749-95.

16. Beatty WL, Byrne GI, Morrison RP. 1993. Morphologic and antigenic characterization of interferon gamma-mediated persistent Chlamydia trachomatis infection in vitro. Proc Natl Acad Sci U S A 90:3998-4002.

17. Kane CD, Vena RM, Ouellette SP, Byrne GI. 1999. Intracellular tryptophan pool sizes may account for differences in gamma interferon-mediated inhibition and persistence of chlamydial growth in polarized and nonpolarized cells. Infection and immunity 67:16661671.

18. Ouellette SP, Hatch TP, AbdelRahman YM, Rose LA, Belland RJ, Byrne GI. 2006. Global transcriptional upregulation in the absence of increased translation in Chlamydia during IFN $\gamma$-mediated host cell tryptophan starvation. Molecular Microbiology 62:13871401. 
517 20. Leonhardt RM, Lee S-J, Kavathas PB, Cresswell P. 2007. Severe Tryptophan Starvation activity by levo-1-methyl tryptophan blocks gamma interferon-induced Chlamydia trachomatis persistence in human epithelial cells. Infection and immunity 79:4425-4437. \&lt;em\&gt;Chlamydia trachomatis\&lt;/em\&gt. Infection and Immunity 75:5105.

21. Thomas SM, Garrity LF, Brandt CR, Schobert CS, Feng GS, Taylor MW, Carlin JM, Byrne GI. 1993. IFN-gamma-mediated antimicrobial response. Indoleamine 2,3dioxygenase-deficient mutant host cells no longer inhibit intracellular Chlamydia spp. or Toxoplasma growth. The Journal of Immunology 150:5529.

22. Stephens RS, Kalman S, Lammel C, Fan J, Marathe R, Aravind L, Mitchell W, Olinger L, Tatusov RL, Zhao Q, Koonin EV, Davis RW. 1998. Genome sequence of an obligate intracellular pathogen of humans: Chlamydia trachomatis. Science 282:754-9.

24. Hogan RJ, Mathews SA, Mukhopadhyay S, Summersgill JT, Timms P. 2004. Chlamydial persistence: beyond the biphasic paradigm. Infection and immunity 72:1843-1855.

25. Beatty WL, Morrison RP, Byrne GI. 1995. Reactivation of persistent Chlamydia trachomatis infection in cell culture. Infect Immun 63:199-205. 
533 26. Ouellette SP, Rueden KJ, Rucks EA. 2016. Tryptophan Codon-Dependent Transcription in Chlamydia pneumoniae during Gamma Interferon-Mediated Tryptophan Limitation. Infection and immunity 84:2703-2713.

536

537

538

539

540

541

542

543

544

545

546

547

548

549

550
27. Ouellette SP, Dorsey FC, Moshiach S, Cleveland JL, Carabeo RA. 2011. Chlamydia species-dependent differences in the growth requirement for lysosomes. PloS one 6:e16783-e16783.

28. Werner RG, Thorpe LF, Reuter W, Nierhaus KH. 1976. Indolmycin inhibits prokaryotic tryptophanyl-tRNA ligase. Eur J Biochem 68:1-3.

29. Hernandez V, Crépin T, Palencia A, Cusack S, Akama T, Baker SJ, Bu W, Feng L, Freund YR, Liu L, Meewan M, Mohan M, Mao W, Rock FL, Sexton H, Sheoran A, Zhang Y, Zhang Y-K, Zhou Y, Nieman JA, Anugula MR, Keramane EM, Savariraj K, Reddy DS, Sharma R, Subedi R, Singh R, O'Leary A, Simon NL, De Marsh PL, Mushtaq S, Warner M, Livermore DM, Alley MRK, Plattner JJ. 2013. Discovery of a novel class of boron-based antibacterials with activity against gram-negative bacteria. Antimicrobial agents and chemotherapy 57:1394-1403.

30. Belland RJ, Nelson DE, Virok D, Crane DD, Hogan D, Sturdevant D, Beatty WL, Caldwell HD. 2003. Transcriptome analysis of chlamydial growth during IFN-gammamediated persistence and reactivation. Proc Natl Acad Sci U S A 100:15971-6. 
551 31. Akers JC, Tan M. 2006. Molecular Mechanism of Tryptophan-Dependent Transcriptional Regulation in \&lt;em\&gt;Chlamydia trachomatis\&lt;/em\&gt. Journal of Bacteriology $188: 4236$.

554

555

561

32. Ouellette SP, Messerli PR, Wood NA, Hajovsky H. 2018. Characterization of Chlamydial Rho and the Role of Rho-Mediated Transcriptional Polarity during Interferon GammaMediated Tryptophan Limitation. Infection and Immunity 86:e0240-18.

33. Østergaard O, Follmann F, Olsen AW, Heegaard NH, Andersen P, Rosenkrands I. 2016. Quantitative Protein Profiling of Chlamydia trachomatis Growth Forms Reveals Defense Strategies Against Tryptophan Starvation. Molecular \& cellular proteomics : MCP $15: 3540-3550$.

34. Lo C-C, Xie G, Bonner CA, Jensen RA. 2012. The alternative translational profile that underlies the immune-evasive state of persistence in Chlamydiaceae exploits differential tryptophan contents of the protein repertoire. Microbiology and molecular biology reviews : MMBR 76:405-443.

35. Wang Y, Kahane S, Cutcliffe LT, Skilton RJ, Lambden PR, Clarke IN. 2011. Development of a Transformation System for Chlamydia trachomatis: Restoration of Glycogen Biosynthesis by Acquisition of a Plasmid Shuttle Vector. PLOS Pathogens 7:e1002258. 
569 36. Johnson CM, Fisher DJ. 2014. Site-Specific, Insertional Inactivation of incA in Chlamydia trachomatis Using a Group II Intron. PLOS ONE 8:e83989.

571 37. Ouellette SP. 2018. Feasibility of a Conditional Knockout System for Chlamydia Based on CRISPR Interference. Frontiers in cellular and infection microbiology 8:59-59.

573 38. Mueller KE, Wolf K, Fields KA. 2016. Gene Deletion by Fluorescence-Reported Allelic Exchange Mutagenesis in \&lt;span class=\&quot;named-content genus-species\&quot; id=\&quot;named-content-1\&quot;\&gt;Chlamydia trachomatis\&lt;/span\&gt. mBio 7:e01817-15.

577 39. Agaisse H, Derré I. 2013. A C. trachomatis Cloning Vector and the Generation of C. 578 trachomatis Strains Expressing Fluorescent Proteins under the Control of a C. trachomatis $579 \quad$ Promoter. PLOS ONE 8:e57090.

580 40. Bauler LD, Hackstadt T. 2014. Expression and Targeting of Secreted Proteins from 581 \&lt;span class=\&quot;named-content genus-species\&quot; id=\&quot;named-content1\&quot;\&gt;Chlamydia trachomatis\&lt;/span\&gt. Journal of Bacteriology 196:1325.

583 41. Miyairi I, Mahdi OS, Ouellette SP, Belland RJ, Byrne GI. 2006. Different Growth Rates of Chlamydia trachomatis Biovars Reflect Pathotype. The Journal of Infectious Diseases 194:350-357. 
586 42. Mendes RE, Alley MRK, Sader HS, Biedenbach DJ, Jones RN. 2013. Potency and

587

588

589

590

591

592

593

594

595

596

597

598

599

600

601

602

603

604 spectrum of activity of AN3365, a novel boron-containing protein synthesis inhibitor, tested against clinical isolates of Enterobacteriaceae and nonfermentative Gram-negative bacilli. Antimicrobial agents and chemotherapy 57:2849-2857.

43. Jakubowski H, Goldman E. 1984. Quantities of individual aminoacyl-tRNA families and their turnover in Escherichia coli. Journal of bacteriology 158:769-776.

44. Pokorzynski ND, Brinkworth AJ, Carabeo R. 2019. A bipartite iron-dependent transcriptional regulation of the tryptophan salvage pathway in Chlamydia trachomatis. eLife 8:e42295.

45. Read TD, Myers GSA, Brunham RC, Nelson WC, Paulsen IT, Heidelberg J, Holtzapple E, Khouri H, Federova NB, Carty HA, Umayam LA, Haft DH, Peterson J, Beanan MJ, White O, Salzberg SL, Hsia Rc, McClarty G, Rank RG, Bavoil PM, Fraser CM. 2003. Genome sequence of Chlamydophila caviae (Chlamydia psittaci GPIC): examining the role of niche-specific genes in the evolution of the Chlamydiaceae. Nucleic Acids Research 31:2134-2147.

46. Ramsey KH, Miranpuri GS, Sigar IM, Ouellette S, Byrne GI. 2001. Chlamydia trachomatis persistence in the female mouse genital tract: inducible nitric oxide synthase and infection outcome. Infection and immunity 69:5131-5137. 
bioRxiv preprint doi: https://doi.org/10.1101/759084; this version posted September 5, 2019. The copyright holder for this preprint (which was not certified by peer review) is the author/funder. All rights reserved. No reuse allowed without permission.

605 


\section{Figure Legends}

607 Figure 1. A flowchart illustrating the events leading to IFN $\gamma$-mediated persistence. By using tRNA 608 synthetase inhibitors to affect translation, a more direct route to persistence is achieved.

Figure 2. Indolmycin and AN3365 effectively reduce recoverable infectious elementary bodies.

611 For all experiments, HEp-2 cells were infected with C. trachomatis L2, and inclusion forming units (IFUs) were collected at $24 \mathrm{hpi}$ and titrated on a fresh monolayer of HEp-2 cells in the absence of antibiotics. A) Indolmycin was added at $120 \mu \mathrm{M}$ at $10 \mathrm{hpi}$. B) Effect of various doses

614 of AN3365 on IFU production when added at 10 hpi. C) AN3365 was added at different times post

615 infection at $1 \mu \mathrm{g} \mathrm{mL}^{-1}$ as indicated. Data are representative of three separate biological replicates. 616 Error bars represent the standard deviation between biological replicates.

Figure 3. Inhibition of tRNA synthetase results in morphological aberrance in C. trachomatis L2.

619 Representative images of HEp-2 cells infected with C. trachomatis and treated or not as indicated.

620 Cells were fixed and stained 24 hpi using primary antibodies to Major Outer Membrane Protein

621 (MOMP) and chlamydial Hsp60_1. Indolmycin and AN3365 treatments resulted in smaller

622 inclusions and morphologically aberrant organisms similar to IFN $\gamma$ treated organisms. All images

623 were acquired on Zeiss LSM 800 confocal microscope with Airyscan at 63x optical magnification 624 with 2x digital zoom. Scale bars represent $5 \mu \mathrm{m}$. 
626 Figure 4. Removal of indolmycin and AN3365 allows reactivation from persistence. HEp-2 cells

627 were infected with C. trachomatis and treated or not with the designated tRNA synthetase inhibitor 628 at 10 hpi. DMEM was removed at 24 hpi followed by three DPBS washes and replenishment with

629 unmodified DMEM. Cultures were allowed to recover for an additional 24 or 48 hours before 630 fixation. A) IFU samples were collected from replicate wells at designated points throughout the 631 experiment. Error bars represent variability between three biological replicates. B) Representative 632 images of untreated C. trachomatis infected HEp-2 cells at 24 or 48 hpi. C \& D) Representative 633 images of indolmycin (C) or AN3365 (D) treated C. trachomatis infected HEp-2 cells at 24, 48 634 (24h reactivation $=$ react.), or 72 (48h react.) hpi. All images were acquired on an AXIO Imager.Z2 635 with ApoTome. 2 at 100x magnification. Scale bars represent $5 \mu \mathrm{m}$.

Figure 5. Immunofluorescent images of HEp-2 cultures infected with C. pneumoniae at 48 hpi show morphological similarity between indolmycin and AN3365 treatments with IFN $\gamma$-induced

639 persistent organisms. Indolmycin and AN3365 were added at 24 hpi. IFN $\gamma$ was added at time of 640 infection. All images were acquired on an AXIO Imager.Z2 with ApoTome.2 at 100x 641 magnification. Scale bars represent $5 \mu \mathrm{m}$.

643 Figure 6. Transcriptional changes in Chlamydia consistent with persistence can be detected during 644 indolmycin and AN3365 treatment. A) Transcripts of euo are elevated in C. trachomatis (Ctr) or 645 C. pneumoniae (Cpn) following treatments with indolmycin, AN3365, or IFN $\gamma$. B) Under standard 646 conditions, groEL_l transcripts in C. trachomatis decrease between 10 and 24 hpi. However, 647 treatment with indolmycin results in unchanged transcript levels, similar to what is seen in IFN $\gamma$ 
648

649

650

651

652

653

654

655

656

657

658

659

660

661

662

663

664

665

666

667

668

669

treated samples, while AN3365 treatment results in higher transcript levels. In C. pneumoniae, no significant change is seen between 24 and 48 hours under any treatment, in agreement with previous reports investigating IFN $\gamma$ exposure. C) $\operatorname{trp} B$ transcripts accumulate at 14 hpi as expected in indolmycin and IFN $\gamma$ treated samples, but not in AN3365. At 24 hpi, AN3365 treated samples exhibit a slight (3-4 fold) increase in $\operatorname{trp} B$.

Figure 7. Transcriptional analysis shows a decrease in readthrough efficiency of the $y \operatorname{tg} A B C D$ operon during indolmycin, AN3365, or IFN $\gamma$ treatment in A) C. trachomatis (Ctr) or B) $C$. pneumoniae (Cpn). RT-qPCR was performed to determine ng of cDNA of both $y \operatorname{tg} A$ and $y \operatorname{tg} D$. Each was normalized to gDNA collected from replicate wells and expressed as a ratio of ng cDNA per ng gDNA of $y \operatorname{tg} A$ over $y \operatorname{tg} D$.

Supplemental Figure 1. Electron micrograph images were collected to examine the morphological impact of indolmycin and AN3365 on C. trachomatis. HEp-2 cells were infected with C. trachomatis at an MOI of 2.5 and treated or not with the denoted tRNA synthetase inhibitor. Samples were collected and fixed at 24 hpi. Images were acquired on an FEI Tecnai G2 TEM operated at $80 \mathrm{Kv}$. Scale bars represent $2 \mu \mathrm{m}, 500 \mathrm{~nm}$, and $500 \mathrm{~nm}$, respectively.

Supplemental Figure 2. Trp deplete media induces an increase in $\operatorname{trp} B$, but not euo, transcripts. HEp-2 cultures were infected with C. trachomatis at an MOI of 1 . At 10 hpi, DMEM was replaced with standard DMEM (Untreated), DMEM lacking trp (No trp), or DMEM lacking trp with 120 $\mu \mathrm{M}$ indolmycin (Indolmycin). RNA transcripts were analyzed via RT-qPCR to compare the 
670 efficacy of trp deplete media in inducing persistence, as measured by increased euo transcript

671 levels.

672

673 Supplemental Table 1. All primer sequences used for qPCR analysis of a given transcript. 


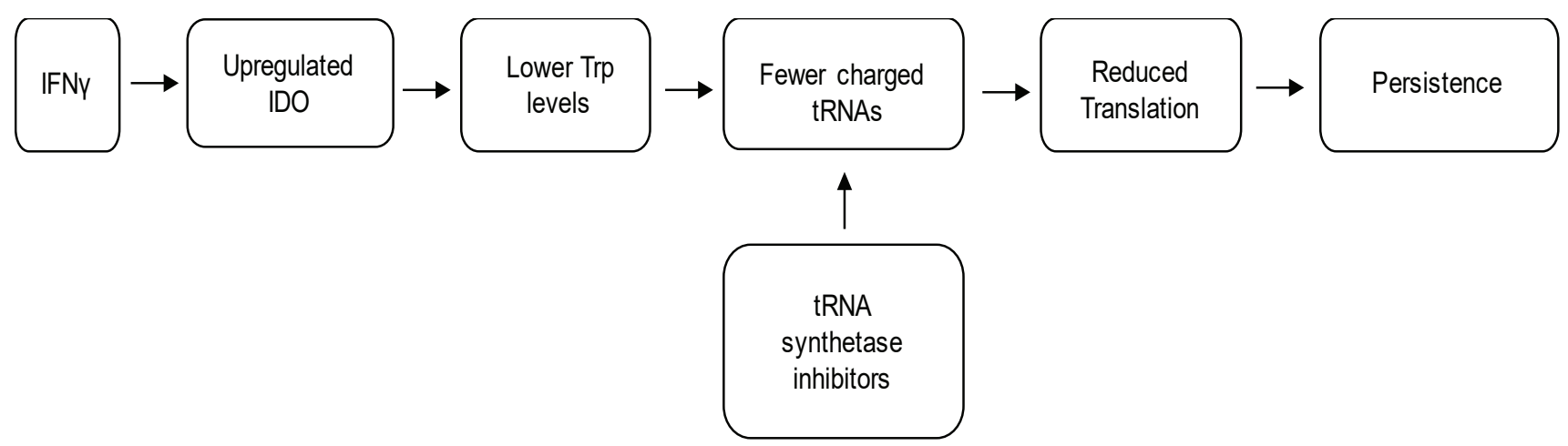

Figure 1. A flowchart illustrating the events leading to IFN $\gamma$-mediated persistence. By using tRNA synthetase inhibitors to affect translation, a more direct route to persistence is achieved. 
A.

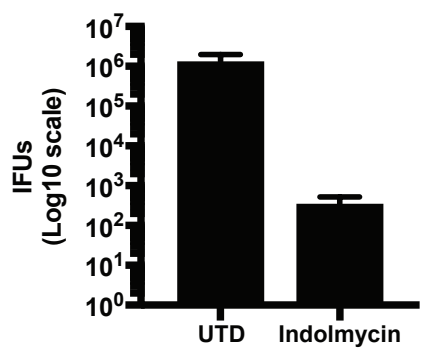

B.

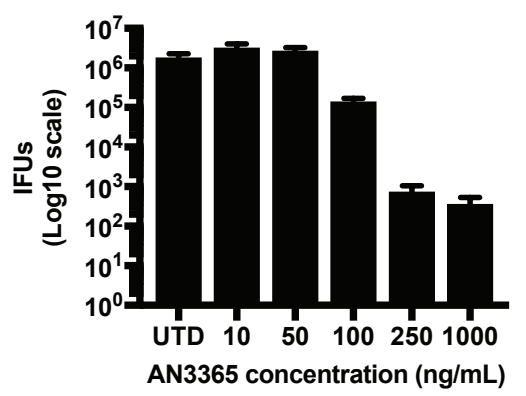

C.

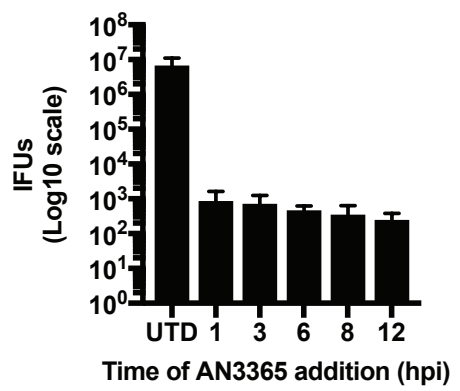

Figure 2. Indolmycin and AN3365 effectively reduce recoverable infectious elementary bodies. For all experiments, HEp-2 cells were infected with C. trachomatis L2, and inclusion forming units (IFUs) were collected at 24 hpi and titrated on a fresh monolayer of HEp-2 cells in the absence of antibiotics. A) Indolmycin was added at $120 \mu \mathrm{M}$ at $10 \mathrm{hpi}$. B) Effect of various doses of AN3365 on IFU production when added at 10 hpi. C) AN3365 was added at different times post infection at $1 \mu \mathrm{g} \mathrm{mL}^{-1}$ as indicated. Data are representative of three separate biological replicates. Error bars represent the standard deviation between biological replicates. 


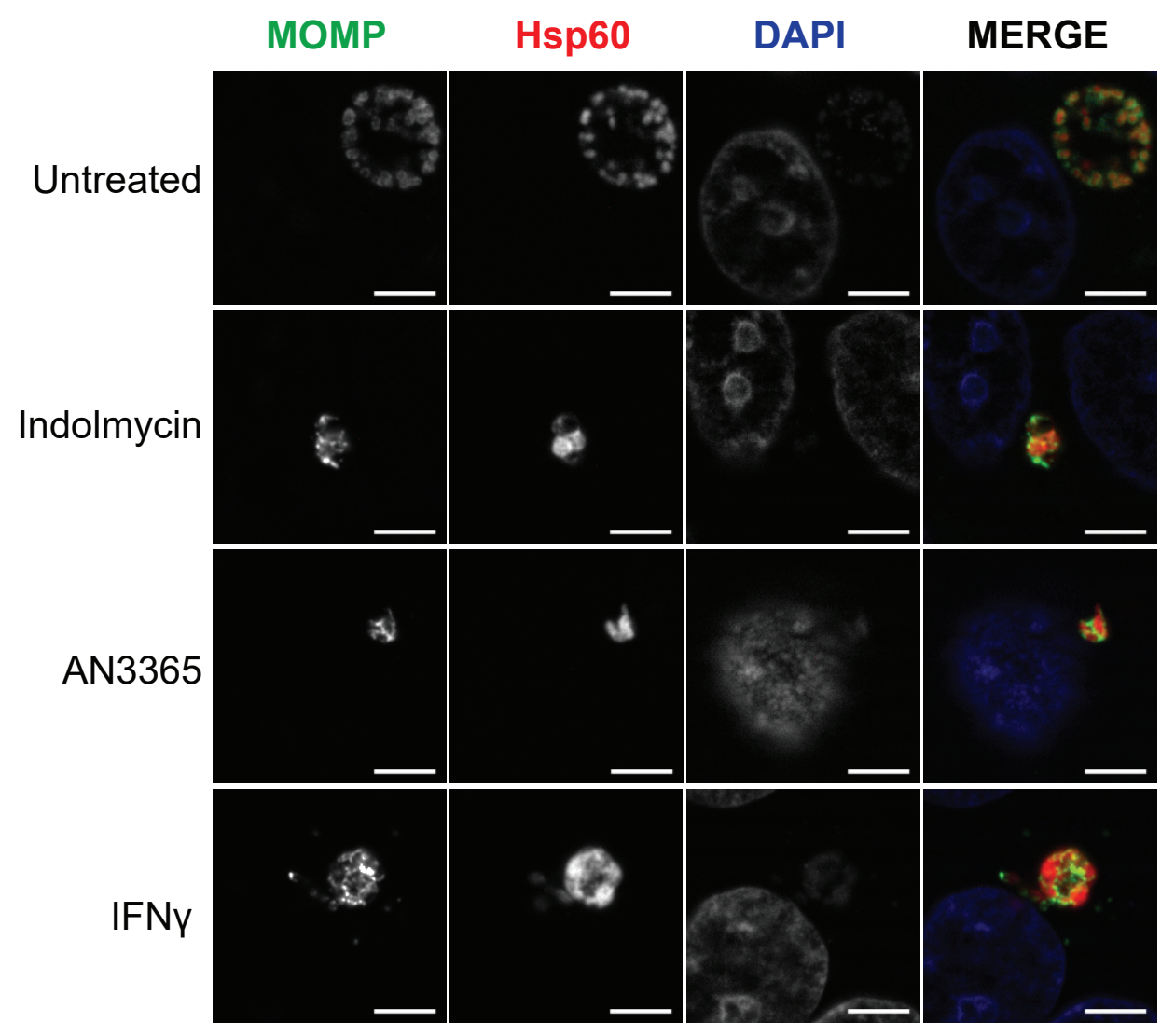

Figure 3. Inhibition of tRNA synthetase results in morphological aberrance in C. trachomatis L2. Representative images of HEp-2 cells infected with C. trachomatis and treated or not as indicated. Cells were fixed and stained 24 hpi using primary antibodies to Major Outer Membrane Protein (MOMP) and chlamydial Hsp60_1. Indolmycin and AN3365 treatments resulted in smaller inclusions and morphologically aberrant organisms similar to IFN $\gamma$ treated organisms. All images were acquired on Zeiss LSM 800 confocal microscope with Airyscan at 63x optical magnification with 2x digital zoom. Scale bars represent $5 \mu \mathrm{m}$. 
A.

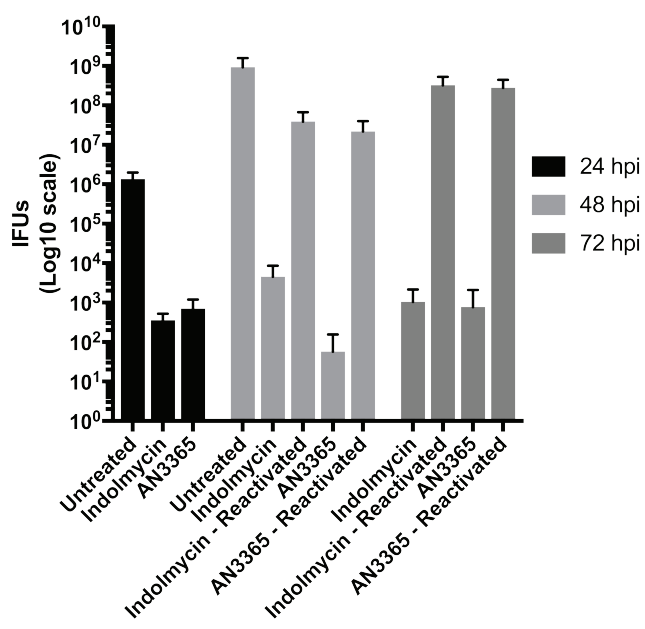

C. Indolmycin

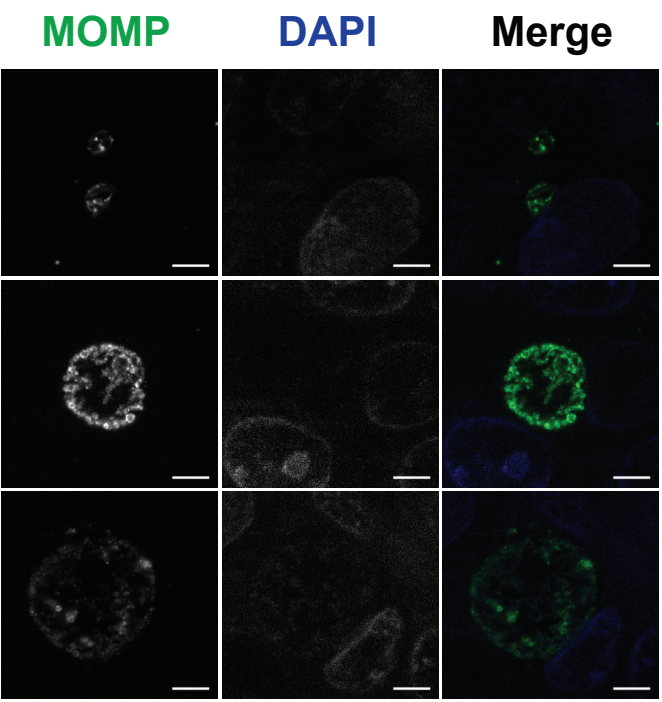

B. Untreated

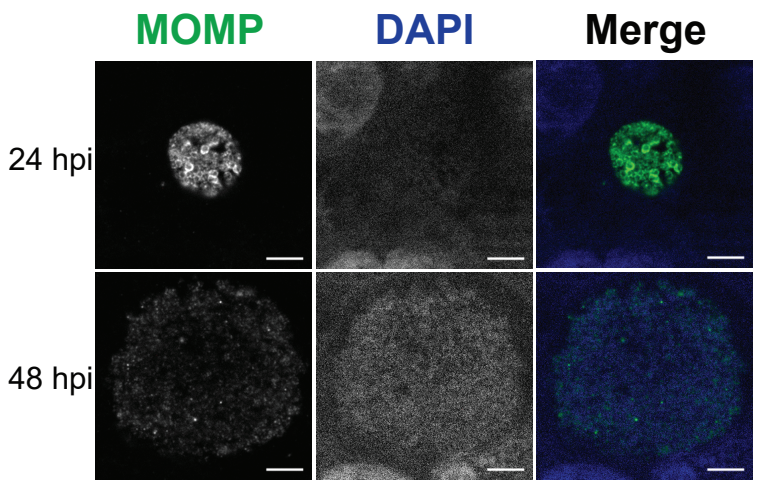

D. AN3365

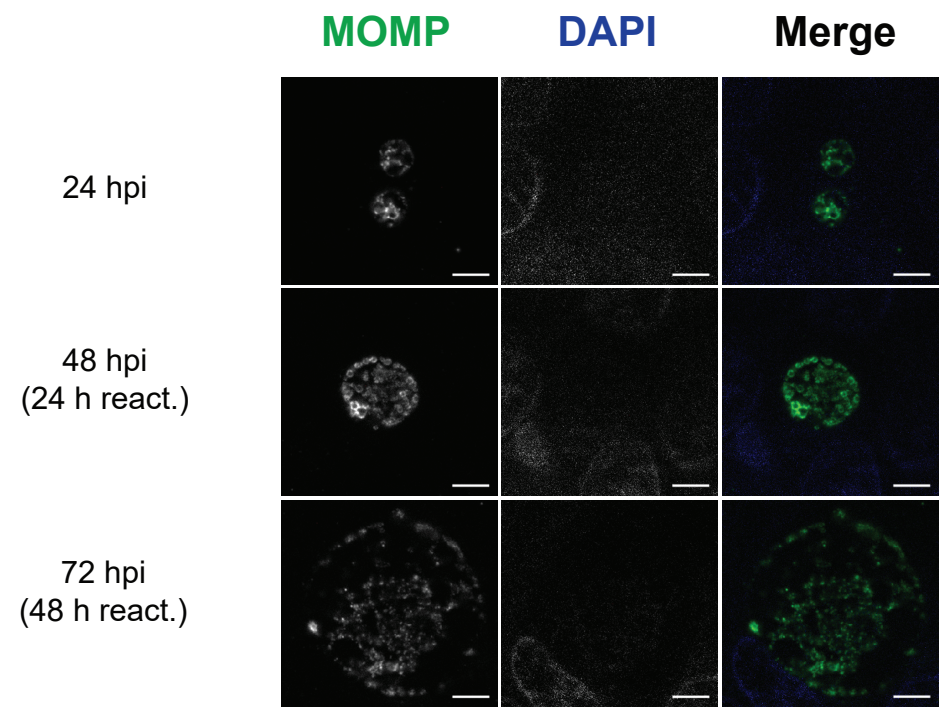

Figure 4. Removal of indolmycin and AN3365 allows reactivation from persistence. HEp-2 cells were infected with $C$. trachomatis and treated or not with the designated tRNA synthetase inhibitor at 10 hpi. DMEM was removed at 24 hpi followed by three DPBS washes and replenishment with unmodified DMEM. Cultures were allowed to recover for an additional 24 or 48 hours before fixation. A) IFU samples were collected from replicate wells at designated points throughout the experiment. Error bars represent variability between three biological replicates. B) Representative images of untreated C. trachomatis infected HEp-2 cells at 24 or 48 hpi. C \& D) Representative images of indolmycin (C) or AN3365 (D) treated C. trachomatis infected HEp-2 cells at 24, 48 $(24 \mathrm{~h}$ reactivation $=$ react. $)$, or $72(48 \mathrm{~h}$ react. $)$ hpi. All images were acquired on an AXIO Imager.Z2 with ApoTome. 2 at 100x magnification. Scale bars represent $5 \mu \mathrm{m}$. 

not certified by peer review) is the author/funder. Aligighter regerved. No reuse allowed without permission.

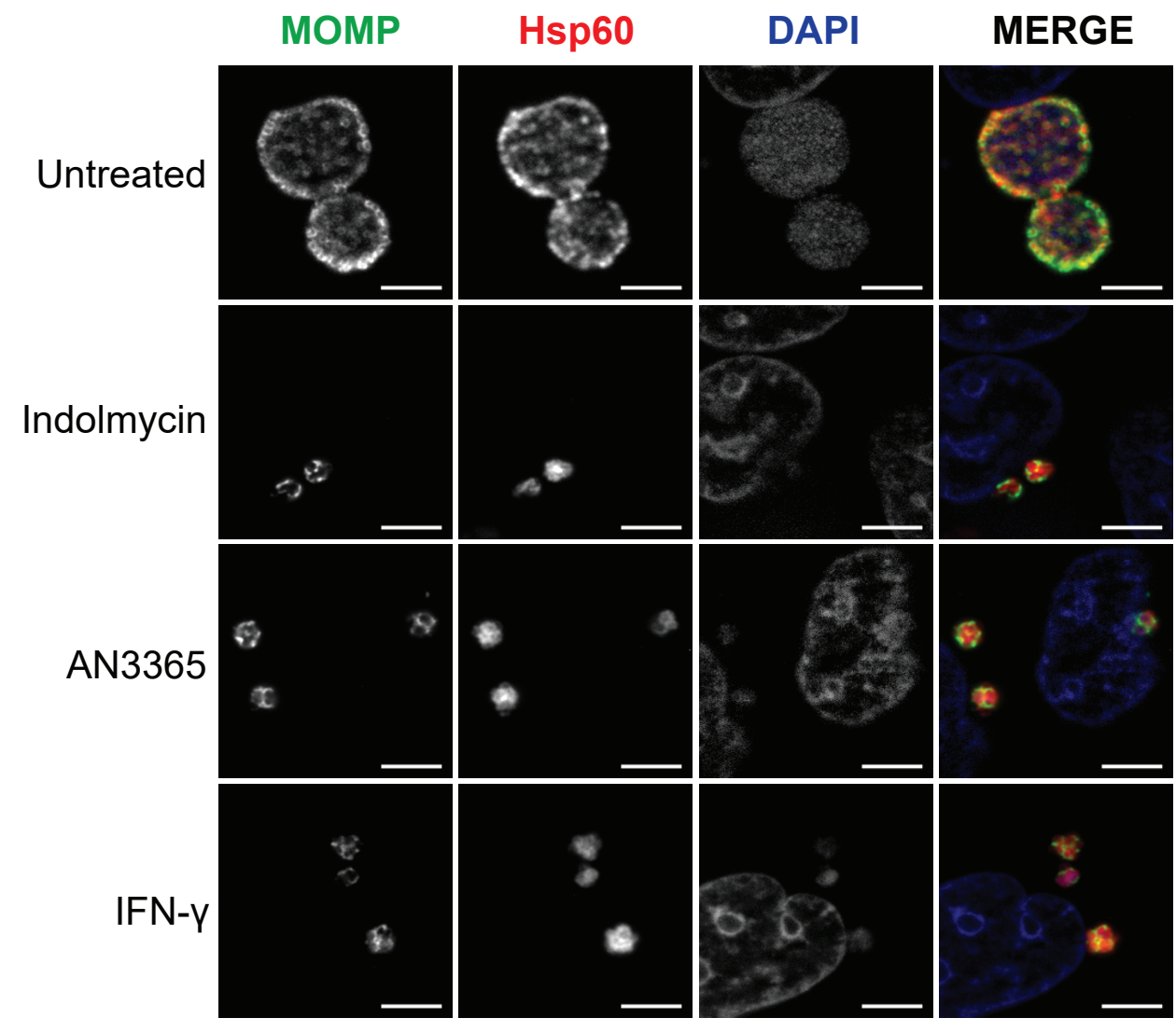

Figure 5. Immunofluorescent images of HEp-2 cultures infected with C. pneumoniae at 48 hpi show morphological similarity between indolmycin and AN3365 treatments with IFN $\gamma$ induced persistent organisms. Indolmycin and AN3365 were added at 24 hpi. IFN $\gamma$ was added at time of infection. All images were acquired on an AXIO Imager.Z2 with ApoTome.2 at 100x magnification. Scale bars represent $5 \mu \mathrm{m}$. 
A.

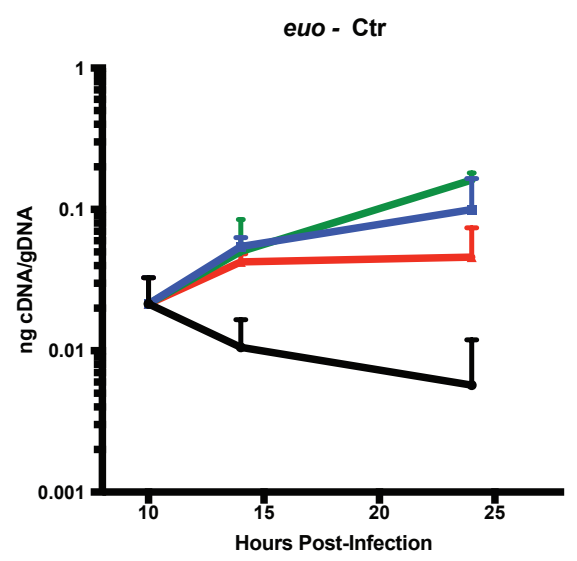

B.

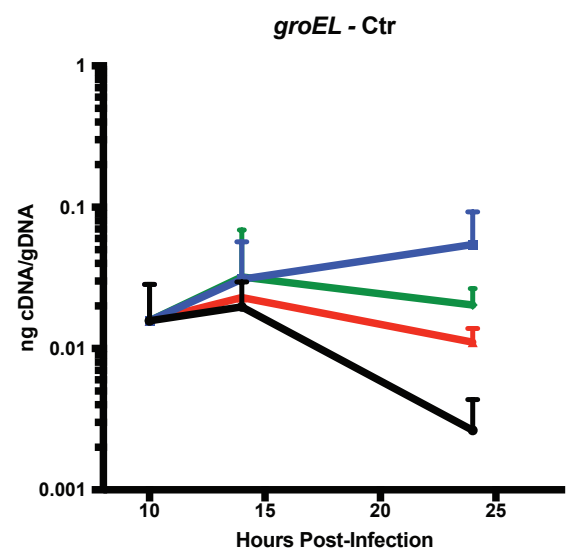

C.

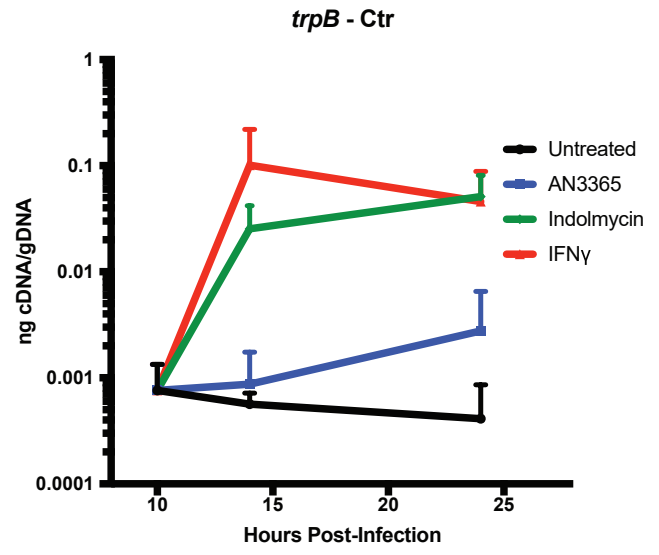

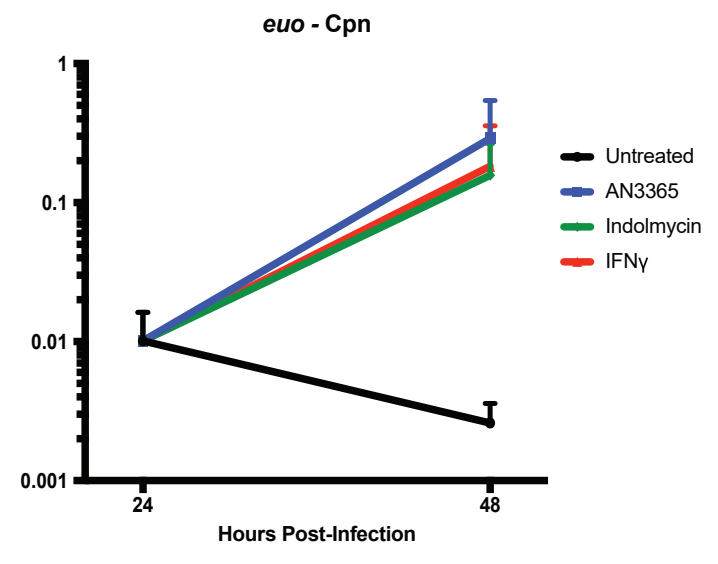

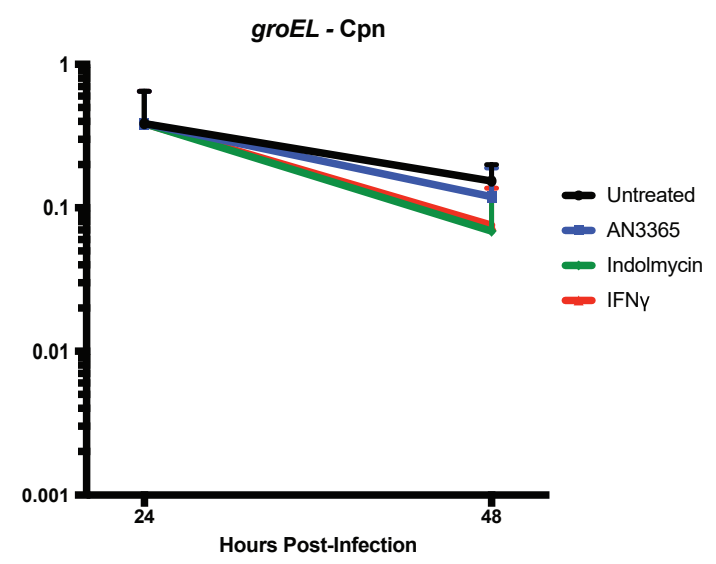

Figure 6. Transcriptional changes in Chlamydia consistent with persistence can be detected during indolmycin and AN3365 treatment. A) Transcripts of euo are elevated in C. trachomatis (Ctr) or C. pneumoniae (Cpn) following treatments with indolmycin, AN3365, or IFN $\gamma$. B) Under standard conditions, groEL_1 transcripts in C. trachomatis decrease between 10 and 24 hpi. However, treatment with indolmycin results in unchanged transcript levels, similar to what is seen in IFN $\gamma$ treated samples, while AN3365 treatment results in higher transcript levels. In C. pneumoniae, no significant change is seen between 24 and 48 hours under any treatment, in agreement with previous reports investigating IFN $\gamma$ exposure. $\mathrm{C}$ ) trpB transcripts accumulate at $14 \mathrm{hpi}$ as expected in indolmycin and IFN $\gamma$ treated samples, but not in AN3365. At 24 hpi, AN3365 treated samples exhibit a slight (3-4 fold) increase in trpB. 
A.

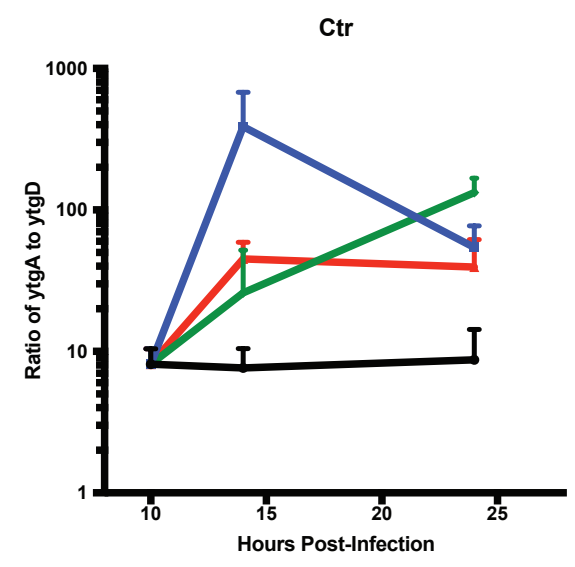

B.

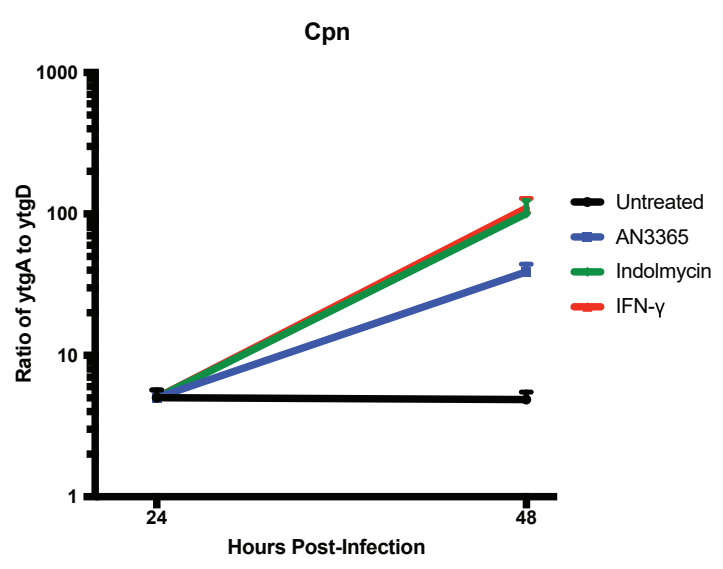

Figure 7. Transcriptional analysis shows a decrease in readthrough efficiency of the $y \operatorname{tg} A B C D$ operon during indolmycin, AN3365, or IFN $\gamma$ treatment in A) C. trachomatis (Ctr) or B) $C$. pneumoniae (Cpn). RT-qPCR was performed to determine ng of cDNA of both $y \operatorname{tg} A$ and $y \operatorname{tg} D$. Each was normalized to gDNA collected from replicate wells and expressed as a ratio of ng cDNA per ng gDNA of $y \operatorname{tg} A$ over $y \operatorname{tg} D$. 